\title{
GOOD PRACTICES IN THE MANAGEMENT OF TOURIST AGENCIES
}

\author{
Irena Emilova, Assoc. Prof., $\mathrm{PhD}^{1}$ \\ Margarita Misheva, Assis. Prof., $\mathrm{PhD}^{2}$ \\ DOI: https://doi.org/10.31410/tmt.2018.529
}

\begin{abstract}
The purpose of this article is to identify good practices and opportunities to provide a competitive advantage to the tour operator business in the contemporary business environment. Specific proposals are made for their achievement, related to the diversification of the offered product and the adding of additional user value; changes in the management of this type of specific activity; automating business processes; designing additional activities; image building, etc. There are also issues, in this paper, related to the application of modern information systems in the management of the activities of the travel agencies. Attention is focused on cloud systems and software services, which, in addition to helping to improve their processes, also provide the opportunity to redistribute resources to manage creative and intellectual processes related to the production of a travel product (packages, excursion routes, etc.) and its placement.
\end{abstract}

Keywords: travel agencies, management, competitive advantage, business information systems, cloud services

\section{INTRODUCTION}

$\mathrm{M}$ odern dimensions of the tour operator business are characterized by a number of features, provoked mostly by globalization in tourism, digitization of the tourist business, personalization of the offered tourist trips, the interest of tourists in products related to experiences, consolidation of the business and the integration processes in it. The role of intermediaries, both on the part of tourists and on the part of tourism service providers, is increasingly being neglected, which has a huge influence on the choice of a strategy for the future development of tour operators.

\section{METHODOLOGY AND GOALS}

The methodology of the present paper includes methodological instruments - the analysis, comparisons and synthesis of available information. The aim of the paper is to study, analyze and systematize good practices in the management of travel agencies. The subject of research is the successful models in management in tour agencies.

\section{ENFORCING COMPETITIVE ADVANTAGE}

As practice shows, the most keen competition is developing in the tourist markets, which have the following characteristics: a large number of simultaneously operating tour operators on the market; possibility of creating and realizing identical tours on the regional market (openness of a local airline to new companies, possibility of cooperation with different meet-companies,

\footnotetext{
$1 \quad$ New Bulgarian University, Department “Administration and Management” Sofia, Montevideo 21, Bulgaria
}

2 New Bulgarian University, Department “Administration and Management” Sofia, Montevideo 21, Bulgaria 
etc.); presence of a number of competing tourist service providers (for example, several airlines based on the local airport, several auto-carriers, representatives of several meeting-companies, which allows easily forming of not expensive and similar travel packages); presence of low entry barriers to enter the tourist market (low purchase or rental price of property, advertising, registration and clearance of documents for tour operator business); high exit barriers to exit the tourist market (high cost of liquidation operations forces even unprofitable travel companies to continue to operate); maturity and saturation of the tourist market.

On the other hand, the emergence of new competitors on the tourism market can be prevented by:

- the joint efforts of existing large tour operators to permanently lower costs and market price of tours (at the expense of concessions granted to a large number of tourists), which would make the offer of the new operator uncompetitive;

- the efforts of big operators to differentiate the offered tours and the transition to brand advertising, highlighting the uniqueness of the offered tourist packages;

- the increase in demand of capital, needed to open a tourist company and carry out tourist activity in the region (for example, additional capital linked to the cost of renting or purchasing fixed assets, advertisement, links and contacts, etc.);

- increasing the cost of training and retraining (training costs and wage increases of specialists);

- the need to set up a new network of agents (i.e. existing network agencies are already in the sphere of influence of the present tour operators and would not want to become agents of newcomers). [1]

Tour operators have one of the most active subjects in the modern tourist market who are directly involved in the planning, development and realization of tourism products. One of the basic tasks of tour operators is the development of attractive tourism products meeting tourists' needs, maintaining good quality tourism services as well as maintaining the competitiveness of these products. Competition between tour operators increases the number of tourist packages as well as the number and type of services included in these packages. Consequently, this leads to the necessity of finding new opportunities and models for the development of competitive tour operator business. [2]

Modern business environment requires tour operators to use a strategy of diversification of their work. It is also a response to the advent of new types of tourism and the motivation of tourists to embark on a specific tourist journey. As part of the diversification of tourism products, in particular the concentric diversification of tourism products, tour operators could benefit from the following identification opportunities for the development of competitive tour operator business through diversification of their products.

The potential tourist is ready to make a purchase by paying for the future consumption of the tourist trip, whose idea implies a certain quality and style. In this decision, he seeks a package of services that satisfy his conscious and unconscious (at the moment) needs. In this context, it should be noted that the user of the product of the tour operator activity is not interested in the product itself or its characteristics but in its utility. On the other hand, the analysis of human needs reveals their immense diversity, and in connection with it, the more needs are satisfied with the purchase of a product, the greater is its attractiveness to the consumer. That is why it is very important for the tour operator to set such parameters in the development of a product strategy, which foresee a continuous renewal of product offering. 
An important guideline in the improvement of the tour operator activity is the tourist's safety and awareness of the conditions of travel and the contractual relationship with the tour operator. One of the main prospects of the tour operators in the future is the provision of a high quality tourist product, which is offered and realized through a large-scale tour network and effective internet advertising. Reservations need to be flexible and not subject to specific check-in and check-out dates. The rich program provided by tour operators needs to be complemented by a variety of package trips and offers based on the personal needs of the clients. [3]

One of the current trends in the management of the tour operator's activities, in connection with the tourist services offered during a tourist trip, is the animator's service. Significant events from the holiday calendar should be included in the annual program plan of the tour operator. The interest of the tourists in certain events, their motivation and the turning of a dream into reality by means of an animation product in which the tourist has personal participation diversifies the program of the trip. This way, tour operators have the opportunity to increase their competitive priority over the rest of the market participants on the market. [4]

It is important for tour operators to:

- keep in touch with different entertainment centers, organizers of carnivals, festivals and other events with the aim of active participation of tourists;

- develop joint scenarios (with animators of tourist sites) of animation programs that should be consistent with the perceptions of the tourists;

- realize full and complex services based on the developed scenarios and having in mind the willingness of the tourists.

The main goal, when including the majority of the activities of tourist and sports animation in the complex services of the tour operator, is to create comfort for the tourists, to provoke their interest so that they feel directly involved in the animation program. This way the whole trip could become the most memorable one that directly responds to the contemporary marketing concepts of creating loyalty of the customer.

The inclusion of cruise trips is another aspect of the expansion of the tour operator's product range. Sea cruise tourism is one of the most popular and fast growing segments on the international tourist market. Cruise tourism offers many advantages for tourists who have a direct influence on such travel. Expansion of the product range on cruises gives tour operators the opportunity to consolidate their positions among their current clients and most of all to meet customer needs. The organization of such journeys is facilitated by the cruise companies who plan the trip and all the clauses in it. In this case, tour operator's responsibilities are in connection with the tourists' transfer to and from the harbor. The tour operator, however, should not underestimate the importance of pre-planning and the negotiations with the cruise company.

Ensuring a competitive advantage can also be achieved by establishing lasting business relationships and developing corporate client programs. There are different instruments used in the management of relationships with clients and among them is the program of loyalty to the customer which largely ensures leadership of a tour operator in terms of continuous competition. The development of a strategy for corporate clients could contribute to a better year-round booking for the tour operator and the increase in revenue later.

The program for corporate clients should focus on offering better prices, fast processing of reservations and documents, organizing events including various additional services, optimizing 
payments and offering discounts for company employees' families. It would also point out that these programs for corporate clients should not be unified but consistent with their individual requirements.

As another good practice, it will point out the development of a network of tour operator representations in tourist destinations. The work of the initiative tour operators abroad is a serious part of the development of tourist trips with total cost. Most Bulgarian tour operators work with local (receptive) tour operators or so-called meet companies. Practice, however, shows that the arrangements between sending and meeting tour operators are not always strictly observed and usually the outgoing tour operators face problems of how to effectively organize their business at the tourist destination where their tourists are on holiday. In such cases setting up offices abroad at tourist destinations could facilitate and ensure tour operator's job especially when organizing summer beach holidays and winter ski holidays. Meeting rooms at the offered destinations could take care of the tourists, which will reflect directly on the image and reputation of the tour operator. All of the meeting rooms are very often connected with transferring tourists from and to airports, accommodation at hotels, offering information for resorts and destinations, offering additional services and excursions, as well as solving problems at destination. All these can be done according to the rules and standards imposed by the tour operator and can be directly controlled so that the tourists can obtain the expected quality. The quality of services, during the tourists' stay at destination depends, to large extent, on the communicative abilities and skills and assiduity of the agents. They are available to tourists and could be contacted at any time and in different unforeseen situations. The tour operator plays a specific role when tourists claim complaints. When there is inadequacy between the contract and the received service, the representative of the tour operator can compensate the tourists right away. Thus, additional familiarity with the complaint can be avoided.

Often, bringing claims also leads to more serious conflict situations. Therefore, effective conflict management would undoubtedly provide a more prominent position for the tour operator in the competitive struggle. In tour operator and tour agency's work very often different in type and content conflicts appear. It can put them in the following groups:

- conflicts where one of the sides is a tourist or group of tourists;

- conflicts with the providers of tourist services and partners of the tour operator;

- conflicts with agents;

- conflicts in the company where the employees are members of the tour operator.

The conflicts of the first group, which usually appear during the trip, have the most serious reflection on the reputation and image of the tour operator. That's why it is necessary when signing the contract, the tour operator to present real, reliable and detailed information about the offered tourist product. It is extremely important to pay attention to the expectations and perceptions of the client of the components of the offered tourist package. It is mandatory for the tour operator to provide competitive advantages in the best possible way between the expectations of the client and the quality of the really received service. It is an important part of the management of conflicts that appear in tour operator activities to set strict rules of behaviour when dealing with conflict situations from different groups of conflicts. In terms of conflicts with providers of tourist services, it is important to mention that they can be avoided by signing contracts with experienced partners, fully shaped rules for cooperation in contracts and continuous improvement of the scheme of mutual cooperation. Presence of detailed contracts with providers, offers for training of agents and realization of better communication among tour operator's employees 
has direct influence on the fulfilment of operational tasks and helps achieve the strategic goal for development of competitive tour operator business.

In this connection, the development of a franchise network can also be part of the strategic goals of the modern tour operator. Franchising is a specific form of trade cooperation and is well known on the Bulgarian market most of all in the sphere of hotel and restaurant business. From an economic point of view, however, franchising is an attractive business model for all participants in the tourism industry, including tour operators, providing an opportunity for sustainable development in the future. An opportunity is given to the franchisor without significant financial investments to effectively use his or her rights to own intellectual property and know-how increase the competitiveness of their products and services and increase their sales on new markets through the use of trade potential and franchisees employees as well as using established relationships with customers. The franchisor increases the profit by receiving payments and saves on expenses as franchisees finance the current business of their firms and hence the entire franchising system. The methods of trade are standardized and the marketing and advertising system is optimized which is sometimes quite difficult when using a net of agents. The opportunity for control is seen as a key moment. The franchisor is given the right to do the entire preventive and current control despite the legal independence of the franchisee.

As the biggest share in providing competitive advantages in the context of the modern dimensions of the tour operator business, it will be noted the automation of business processes. The efficiency of modern management is largely based on the application of information technologies, which allows for automation and optimization of a large number of business processes in tourism firms. The information systems are today a powerful organization and management resource tools; that is why design and implementation of information systems has never been more relevant. Thus, ERP (enterprise resource planning) is a necessity more and more for all types of businesses, regardless of their size and field of development.

The ERP (Enterprise Resource Planning) system is a computerized multivariable and multifunctional system based on client-server technology, a business model for the planning, control, global optimization of the entire logistic chain of the process of supply, production and trade of products and accompanying financial operations. Systems of this type create prerequisites for fast growth in tour operator business. Owners of small tourist agencies, very often do not have such business systems built that can multiply itself without their participation ensuring growth. Such tour operators almost always depend on a few important employees (very often they are the owners themselves) who, with the development of business, become more and more busy. There is a lack of know-how for managing growth and business to be converted into a working system. With the implementation of ERP system and readymade type of automated management is introduced and the business in practice starts faster expansion. The new work practices that software for business management creates for employees and managers optimize their work. They save time, increase the productivity of the whole team and create the opportunity to concentrate efforts on developing new programs and routs.

Tour operators who use the ERP system have at their disposal powerful tools for accounting, human resource management, finance, deliveries and trade, and very often it allows them to successfully enter the territory of competitors who have significantly more assets and turnover.

With the help of ERP systems, and depending on their needs, managers of tour operators can run accounting reports for the effectiveness of tour operators as a whole, for managers' work in 
offices, profitability of advertisements, etc. Analytical reports provide the opportunity to have centralized statistical information for all offices or for specific offices and managers. Information during sales for all offices, for example, will determine the weakest at sales and then the weakest agent will be identified and all this can be presented dynamically by months and days. Reports on the margin and the volume of sales are presented by directions and agents, which allows tour operators to check in detail the given commission or bonuses.

The implementation of ERP systems and the creation of unified information space for tourist packages is a key aspect for the successful management of business processes in tourist businesses and especially tour operators.

One of the basic problems of modern tour operator's businesses, which are directly connected to the base of tour operators for tourist agents, can be solved by using the system for automation of management processes (ERP). The need for such type systems stems from the opportunity of all the processes associated with the tour operator and administrative activities to be controlled as well as the management of relations with agents and suppliers.

Focusing on the contemporary dimensions of the tour operator business, it need to note the provision of competitive advantages through the development of project proposals for the purpose of applying for European programs.

Recently intensive growth of activities in the sphere of NGO organizations and in private business is observed in Bulgaria in connection with the development of projects for participation in European programs. This applies to the entire tour operator business in front of which an opportunity in this direction opens. For example, tour operators can apply for the Competitiveness and Innovation Program 2014-2020 which supports the technological development and use of innovations in enterprises. The implementation of such projects should provide the realization of products and services that fall within the scope of the mentioned priority directions of the thematic fields of the Innovation strategy for intelligent specialization, including information and communication technologies, as well as creative and re-creative industries.

The development of such projects can enhance the competitiveness of a certain tour operator and impose its image in the society when it participates in joint projects related to regional development and overall improvement of the conditions and standard of living in the city and region in which it operates. [5]

\section{APPLICATION OF MODERN INFORMATION SYSTEMS IN THE MANAGEMENT OF TOURIST AGENCIES}

Nowadays, information technologies play a major role in our lives. Apart from consumer needs, they also have a huge impact on business. Already all major international companies apply information systems to gain useful information about their business by providing a competitive advantage. Until a few years ago, the business applications that were used relied mainly on client-server technology. However, as a result of the global financial crisis, most of the companies have reduced their spending and are increasingly turning to the cloud environment that allows businesses, including travel agencies, to take full advantage of the software's capabilities without pay the expensive hardware prices. An increasing number of large business applications 
have adopted the idea that the future is in the cloud environment, so they have begun seriously to devote resources to developing and maintaining information systems within it. [6]

The market of cloud technologies (cloud computing market) in the world is huge. According to Deloitte data [7] in 2008, this business has earned $\$ 55$ billion in revenue, and two years later the volume is already $\$ 70$ billion. By the end of 2012, according to Gartner, Inc., Business process services, compared to the previous year, was $19.6 \%$, and the total transaction volume was $\$ 109$ billion. Technology is now well known in both the corporate and public sectors. In the USA, for example, cloud technologies have state support and are being used by the congress and the administration of the president. According to a study by the European Centre for Economic Policy Studies, if EU countries actively implement cloud technologies, Member States can save 760 billion euros in just five years and find 2.4 million new jobs. In tourism, cloud systems are only making their first timid steps, but experts are convinced they will enter quickly because of their advantages.

Cloud Services are an evolutionary solution of the started years ago automation of the business with mainframe technologies that migrate to client servers and then to the Internet. It should be noted, however, that cloud services and outsourcing are not the same thing, although they are very similar. The main difference, with the outsourcing, is that there is a company that uses a service provided by another company, that is, the connection is one client - one contractor, whereas in cloud computing, many customers receive the same service from a single provider - the so called "multitenancy".

The leading global cloud computing companies are Amazon, Microsoft, Oracle, Citrix, IBM, Hewlett Packard, Salesforce.com, Google App Engine. The most common cloud model is server - infrastructure - platform - application - client. According to experts in this area, the main factor that slows the development of ,,cloud technologies” is safety, namely the lack of client control over the server, the processes, the possibilities of leakage of important information. According to other experts, these doubts are unfounded, as for activities such as internal accounting, Customer Relationship Management (CRM), Human Resources (HM), and others, they are a very convenient way of facilitating work and reducing costs.

Examples of cloud systems outside the business are well-known Facebook, YouTube, Skype, LinkedIn, where personal information is stored. Microsoft offers cloud disk space for free, along with its licenses. Apple also has a cloud for its users - iCloud. Many of Microsoft's products can also use a cloud, which implies not buying a license but paying monthly fees. The files are stored on a cloud hard drive and the applications themselves are installed on cloud infrastructures (server), so they are used through a browser, which implies the availability of the Internet.

Much of the business software solution is also now available in cloud systems, making it easier for businesses, including travel agencies, to use them, as there is no need to purchase expensive servers and server operating systems. For example, small and medium-sized travel agencies, which are predominant in Bulgaria and lack sufficient financial resources to maintain an IT department or provide special premises for their own local server, could benefit from the benefits of cloud systems. [7]

The benefits of cloud services are also associated with cost reduction and control, trusting data care and used by travel agencies system in the hands of specialists, easy adaptation of the neces- 
sary IT resources to the peaks and drops of sales in the business environment; real-time access to the most up-to-date business data is tailored to the role and needs of each travel agency.

Cloud technologies consist of a variety of types of services available to any user on-demand. The main types of cloud services or, more precisely, service-by-service are [8]:

- Software as a Service (SaaS) - with this model, the provider provides customers with access to licensed software applications that are installed on the cloud. Users can access these applications over the Internet through a web browser by applying a pay-per-use model. Users are not busy managing or controlling cloud infrastructure elements such as a network, server, operating system, or data repository. In general, the service provider has and maintains the application that is hired by virtual machine customers in the cloud environment. SaaS is available from leading manufacturers such as Soho Suite, Apple's MobileMe and Google Docs.

- Platform as a Service (PaaS) - Providers provide customers with a programming language such as a platform or software such as Java, Python or .Net, etc. to deploy their own or third party applications to the cloud infrastructure and make them accessible via the Internet with APIs (Application Program Interfaces) or website portals for their clients. Customers have control over the developed applications and, to a certain extent, the settings of the hosting environment. As with (SaaS), customers have no control over the underlying cloud infrastructure such as network, servers, operating system, and disk space. Examples of Platform-As-Service Providers (PaaS) are Google App Engine, Force.com and Microsoft Azure.

- Infrastructure as a Service (IaaS) - cloud infrastructure providers as a service provide customers with the ability to use computing power, disk space, Internet network, memory and other basic technological resources that make possible the deployment and performance of various software programs such as operating systems and applications. Infrastructure-like-Service also provides a virtual environment as a service where customers have control over themselves to determine the memory modules, CPU usage time, number of IP addresses, operating system, installing software applications as well as additional network components such as firewall (firewall), load balancers and more. Customers do not have access to the basic cloud infrastructure, but only determine the parameters of their own virtual machine. Examples of Infrastructure-As-Service Providers (IaaS) worldwide are Amazon EC2 and S3, Sun Microsystems and Dropbox.

- Integration as a Service (IaaS) - Integration-as-Service (IaaS) is a cloud model that introduces functional system integration into the cloud system, allowing for the exchange of information between the systems of the individual organization and third parties (suppliers or partners) upon request. Small and medium business organizations use Integration as a Service (IaaS) for the ability to integrate all types of business services at low cost, enabling them to target resources to their core business instead of purchasing and managing expensive IT infrastructure. Famous IaaS service providers are Amazon SQS, OpSource Connect, Boomi and Mule On-Demand.

- Business Process as a Service (BPaaS)) - Business Process-as-Service (BPaaS) refers to any business process within the cloud technology model (self-service provision, elastic scaling and measurement consumption or pricing, processing of wages or human resources) accessed through the Internet through web-based interfaces and using webbased cloud architecture.

- Desktop as a Service (DaaS) - Desktop-like-service (DaaS) is also known as a virtual desktop or desktop rental and is a transformation of desktops in a cloud service. There are two main categories of DaaS - those based on local performance and those using 
centralized (remote) performance. For the time being, there is only one form of DaaS, within a category of local performance, and this is the approach of MokaFive. Sometimes this model is called a cloud-based desktop because it's the true essence of the service - virtual desktops stored in the cloud (from MokaFive) and downloaded on-demand on the computers of users where they work at local level. Currently, DaaS is executed locally by storing and downloading on request from the cloud, which somewhat differentiates this service from the typical cloud services where all processes are performed in the cloud.

- Testing as a Service (TaaS) - the purpose of this model is to enable organizations to carry out proof-of-concept tests before deciding whether to change the current infrastructure with clouds such as using emulators such as iTrinegy. This service allows customers to monitor the impact of important network factors such as packet loss, bandwidth, latency, and response time as conditions for making better decisions.

- Management as a Service (MaaS) - Management as a Service is an on-demand service that provides the ability to manage one or more cloud services such as topology, resource usage, virtualization and management of accessibility (uptime). The Cloud Management Platform CMP contains a set of tools for business and operational management. MaaS enables customers to manage their cloud services from each category in self-service mode.

- Security-as-Service (SecaaS)) - Security as a Service refers to the delivery of secure platforms and applications to customers on demand. If security is entirely under the control of the vendor, customers will feel the lack of control over their personal data.

The most common application is Cloud Services SaaS (as 70\% of the time), Infrastructure-like-Service-IaaS and PaaS-as-Service.

An example of implementing a cloud service like SaaS-like service is the realization of the idea of better business process management in Dertour Bulgaria. Dertour Bulgaria is the official representative for Bulgaria, Macedonia and Albania of DER Touristik - one of the leading tour operators in Europe. The company offers a huge range of products, both in the field of individual and package travel - over 25,000 hotels worldwide, about 240 airlines, 80 cruise companies, 30 rental companies and more.

Dertour Bulgaria [9] was founded in 2006 to introduce and develop DER Touristik's products on the Bulgarian tourist market, where the company's products are sold by more than 100 travel agencies and many of them are also available online. In 2013, Dertour Bulgaria switches to cloud services using the MS Office 365 software. The idea for a change in the infrastructure of Dertour Bulgaria is due to the problems the company has in its previous way of working - a local mail server with configured POP3 accounts on client computers, where emails are constantly being lost. Until the product was deployed, several employees had used a common email client to contact, which made tracking difficult, including the responses sent. Among the main drawbacks of the old model of work is the frequent interruption of power and Internet service by the provider for a longer period of time, which also stops receiving mail, since when a local server is turned off, there is no service to accept the letter, and returns to the sender with an error. After the implementation of the cloud service in the tour operator, the use of the so- categorization in general posts between employees. Each employee has their own category, which marks the letter when it begins to work on it. Any other employee who works with this mail sees the category and assumes the next task. This makes it easy to see who worked on the ticket application, for example, and the subsequent correspondence. It also provides the ability to note the status of a particular task 
and this is visible to all employees, so the manager is aware of which email is currently being processed and by whom. Until the cloud service was introduced for the purpose of collaborative work, employees were required to gather at the end of the working day to discuss the status of all received messages and to update the extent of their processing. Managing the process is also facilitated by the ability of employees to access mobile devices across all popular platforms - iOS, Blackberry, Android, Windows Mobile 8. In addition, two-way synchronization between contacts and a calendar is made that allows employees to have everything they need to do their business both from the tour operator's office and from the various tourist sites during a trip or other mobility. Through the cloud structure, employees also have corporate OneDrive, or so-called. „Company's cloudy flash". This is a space for uploading information to each user that some employees can access if the sharing function is used. This helps with daily work with files to be sent, processed by different devices, etc., and synchronization with the user's computer is currently taking place.

This infrastructure creates many upgrade capabilities, including the implementation of Sharepoint, which in the broadest sense means a corporate website. Only tour operator employees have access to it and they can only have the published information (without access by travel agents). This creates convenience for long-term projects related to the planning and organization of a tourist trip, which in general can last from a few weeks to a year or two, and in which a large number of employees are involved. The solution provides the opportunity to introduce much of the business information for contractors (agents, transport companies, hotels, etc.) to which all or parts of employees should have access by setting different levels of access.

Site information is derived from DER Touristik's reservation system, which allows you to check the price and availability of tens of thousands of hotels worldwide, and the whole process is fully automated. In its daily work, the company also relies heavily on an ERP system that provides the link between bookings and accounting. It also has a CRM module that provides easy database operation.

On the Bulgarian market, software products related to pricing are already available as part of business management systems. Typically, this is a sales product module that is used for flexible pricing and pricing for tourism products by tour operators. The tool allows you to automatically calculate prices by a given formula, individual pricing method for each product group individually, as well as a pre-betting cost of product acquisition and planned profit. For example, the pricing of the product group, which includes package bus breaks or charter schedules, can be done much faster as it allows processing multiple price lists at the same time (at different hotels or airlines). Each price list in the company can be managed individually, and managers can directly compare the current price with the new one derived from pricing. In addition, the ability to set types of acquisition costs and margins is also provided.

One of the most widespread applications of SaaS cloud systems in tour operator and tour agent activity are reservation systems. A large number of Bulgarian travel agencies use reservation systems that are entirely dedicated to domestic and foreign tourism and which offer the opportunity to reduce customer processing time by up to $60 \%$, as well as to analyse business processes [10].

The main advantages of this type of system are related to:

- Automatic contract generation, voucher, query, confirmation, documents can be printed, generated in PDF and sent via email directly from the system.

- Automatically generate a hotel reservation, a transport company, and more.

- Introduction of more services of one type (hotel accommodation, transport, transfer, etc.) by generating one contract and the necessary number of vouchers to it. 
- Issuance of invoices, cancellations, credit notifications by automatic generation and numbering of documents.

- Track revenue payments by tracking individual bookings, tracking reports for groups, booking by periods, and more.

- Track payment charges by tracking the amounts due on services and reservations, as well as amounts due and paid by suppliers.

- Management of cash registers and bank accounts through accounting tracking of accounts, automatic generation of a daily cash register and review of account balances.

- Total cost management by tracking and analysing costs such as rents, insurance, utilities, and more.

- Sales management through sales trend analysis, cash flow analysis, product factor analysis, balance analysis.

- Automatically generate lists - a mailing list, shipping lists, and more.

- Client database management through quick reviews and easy entry.

- Database management with vendors and corporate clients through quick reviews and easy entry.

\section{CONCLUSION}

In conclusion, it can be pointed out that a complicated and dynamic business medium, where modern tour operators are forced to work, demands that they apply different methods and approaches to increasing their competitiveness. The complicity is determined by the quantity and the similarity of the factors influencing the external medium. The dynamic originates from the fast pace of changes in the medium, regardless of how stable it is. The complicity and dynamics determine the specific approach to organizing the activity of the tour operator and the peculiarities of its management.

Tourism organizations and, in particular, travel agencies have always been active participants in the deployment of innovative technologies, including global information systems. Modern achievements in the field of telecommunications, networking, creation and processing of databases provide new opportunities for their development. Practice shows that implementing different IT systems in travel agencies not only improves their business processes but also reduces costs by helping to achieve the company's most fundamental goal, namely profit.

The role and importance of modern information systems are strategically important for the development of travel agencies in the dynamically changing external environment in which they operate. They allow optimizing and, in many cases, automate the information processes in the activity of travel agencies, which helps to redistribute resources to manage the creative and intellectual processes related to the production of tourist product (packages, excursion routes, etc.) and its sale. Cloud systems are an up-to-date and promising tool for developing corporate connections between tour operators, tour operators and tourism service providers in managing information during travel trips. 


\section{REFERENCES}

[1] Falzon, J., (2012) The price competitive position of Mediterranean countries in tourism: evidence from the Thomson brochure, Elsevier Ltd, Amsterdam, Netherlands, p. 8

[2] Misheva, M., (2013), Consulting tour operators in developing destination, Avangard Prima, Sofia, p.78

[3] Font, X., Oliveros, M., Clark, G., (2009) Capacity building of Nepalese incoming operators for sustainable management and marketing, International Centre for Responsible Tourism, Leeds Metropolitan University, Leeds, UK, p. 9

[4] Cheng, J.C, ChengShiung, W., ChangHua, Y., Yu, C. C., (2016) Tour leader attachment and customer citizenship behaviors in group package tour: the role of customer commitment, Routledge, Abingdon, UK, Asia Pacific Journal of Tourism Research, p. 18

[5] Misheva, M., Innovation in the Management of Tour Operator's Activities, Collection of Reports from the Anniversary International Scientific Conference „Tourism in the Age of Transformation", Science and Economics, Varna, p. 338-339

[6] GonzÃ lez, A.M. \& Bello, L. (2002) The construct 'lifestyle' in market segmentation: the behavior of tourist consumers. European Journal of Marketing, 36(1/2), pp. 51-86.

[7] Laskey, H.A., Seaton, B. \& Nicholls, J.A.F. (1994) Effects of strategy and pictures in travel agency advertising. Journal of Travel Research,32(4), pp. 13-19.

[8] Cloudy Technology Models to Provide Services, http://blog.icn.bg

[9] The Experts, Travel and Hospitality Experts (2013), 4 issue, Year II, https://thexperts.bg/

[10] Cloud Technology Increases Duratour Bulgaria’s Job Performance, http://cio.bg

[11] http://www.rvertis.com 